\title{
INFRAESTRUTURA PÚBLICA E CRESCIMENTO DOS MUNICÍPIOS BRASILEIROS: ANÁLISE ESPACIAL ENTRE 1970 E 2010
}

\author{
Graziella Magalhães Candido de Castro* \\ Rudinei TONeto JR. ${ }^{\dagger}$
}

\begin{abstract}
Resumo
Este artigo estuda a relação empírica entre infraestrutura pública e crescimento econômico dos municípios brasileiros entre 1970 e 2010. Para isto, generaliza-se o modelo de crescimento econômico regional desenvolvido por Glaeser et al. (1995) incorporando o capital público na função de produção das firmas. Para estimação, opta-se por um método econométrico capaz de acomodar heterogeneidade e dependência espacial entre os municípios. Os resultados sugerem que o acesso à energia elétrica e ao abastecimento de água afetam positivamente o crescimento do salário per capita. Considerando crescimento populacional, encontra-se efeitos positivos do acesso à energia elétrica e à coleta de esgoto.
\end{abstract}

Palavras-chave: crescimento econômico regional, infraestrutura, econometria espacial

\begin{abstract}
We study the relationship between public infrastructure and economic growth of Brazilian municipalities between 1970 and 2010. We generalize the regional economic growth model developed by Glaeser et al. (1995) incorporating public capital in the production function of firms. As municipalities are assumed to be subjected to various forms of spatial interaction, we use an econometric method capable of accommodating heterogeneity and spatial dependence between municipalities. The results suggest that access to electricity contributes positively to regional economic growth, access to sewage collection has positive effects on population growth and access to water supplies has positive impacts on per capita wage growth.
\end{abstract}

Keywords: regional economic growth, infrastructure, spatial econometrics

JEL classification: O18, R11, R15, R53, R58.

DOI: http://dx.doi .org/10.11606/1980-5330/ea115755

\footnotetext{
*Universidade Federal de Viçosa. E-mail: graziella.magalhaes@ufv.br

† Universidade de São Paulo. E-mail: rtoneto@fearp.usp.br
} 


\section{Introdução}

Este artigo pretende estudar a relação empírica entre a infraestrutura pública e o crescimento econômico dos municípios brasileiros entre 1970 e 2010 . Entende-se como infraestrutura o conjunto de instalações e equipamentos de uma economia que permitem a produção e o fluxo de bens e serviços. Dentre as principais características desse tipo de capital estão a reduzida mobilidade, altos custos irrecuperáveis, baixa relação produto-capital e elevada escala produtiva (Mussolini \& Teles 2010). Ademais, como costumam apresentar externalidades positivas e altos retornos sociais, em geral, os investimentos em infraestrutura são feitos majoritariamente pelo setor público.

O interesse nos efeitos da infraestrutura pública sobre o crescimento econômico tem sido alvo de extensa pesquisa teórica e empírica. Grande parte da literatura teórica considera o estoque de infraestrutura pública como um insumo adicional e complementar na função de produção agregada da economia. $\mathrm{O}$ aumento do estoque em infraestrutura afetaria o produto tanto diretamente, como por meio do efeito "crownding-in" sobre os demais insumos (Arrow \& Kurz 1970). Ao aumentar a produtividade marginal dos outros fatores de produção, a infraestrutura pública estimula um aumento no investimento privado e no produto.

Deve-se notar, porém, que a arrecadação de impostos necessária para financiar os investimentos em infraestrutura pode desincentivar investimentos privados, compensando os efeitos de crownding-in sobre a produtividade dos fatores de produção. Barro (1990) explora essa dualidade da participação do governo na economia a partir de um modelo de crescimento econômico endógeno. De acordo com o autor, para maximizar o crescimento econômico, o governo deveria gastar até equalizar a fração do gasto público produtivo em relação ao PIB à elasticidade do produto com relação ao gasto público. Futagami (1993) estendem o modelo de Barro (1990) incorporando o estoque de capital público. Apesar das dinâmicas de transição se tornarem mais complexas, os resultados com relação ao crescimento econômico não se alteram.

Além das relações descritas anteriormente, a literatura sugere ainda outros possíveis efeitos da infraestrutura sobre o crescimento. Hulten \& Schwab (2000), Bougheas (2000) e Agénor (2013) sugerem que a infraestrutura é um determinante da produtividade total dos fatores (PTF) e, portanto, possui efeitos sobre o crescimento do produto. Turnovsky (1996) e Agénor (2011) ressaltam o efeito da infraestrutura sobre a acumulação de outros insumos. Assim, a fração do investimento em infraestrutura que maximiza o crescimento econômico não é dada apenas pela elasticidade do produto em relação a infraestrutura, mas deve considerar seu efeito sobre a acumulação dos fatores de produção privados.

A literatura empírica corrobora os resultados teóricos ao indicar efeitos positivos da infraestrutura sobre o nível e a taxa de crescimento do produto e da produtividade. Aschauer (1989) sugere que o aumento de $1 \%$ no estoque do "núcleo" do capital público aumentaria em 0,24\% a PTF ${ }^{1}$. Munnell (1990) mostra que o aumento de $1 \%$ no estoque de capital público aumentaria em $0,34 \%$ o produto ${ }^{2}$.

\footnotetext{
${ }^{1} \mathrm{O}$ núcleo é composto por ruas, estradas, aeroportos, instalações de gás e elétricas, transporte coletivo, sistema de águas e esgoto.

${ }^{2} \mathrm{O}$ forte efeito do capital público alocado em infraestrutura encontrado pelos autores gerou
} 
Como salientado por Calderón \& Servén (2014), ainda há pouco consenso sobre a magnitude desses efeitos. O maior consenso está entre os artigos que utilizam indicadores físicos da infraestrutura como variável explicativa. Trabalhos mais recentes abrangendo vários setores de infraestrutura encontraram resultados positivos e significativos da infraestrutura sobre o produto e produtividade (ver Canning (1999), Calderón \& Servén (2003)). Com relação aos efeitos de longo-prazo, Sánchez Robles (1998) e Calderón \& Servén (2004, 2010) encontraram que estes indicadores são positivamente relacionados com o crescimento do PIB per capita de países industrializados e em desenvolvimento.

Para o caso brasileiro, embora os estudos variem bastante quanto a metodologia e a abordagem econométrica, os trabalhos indicam majoritariamente que o impacto produtivo da infraestrutura pública no Brasil é relevante (ver Ferreira (1996), Ferreira \& Malliagros (1998), Ferreira \& Araújo (2006), Mussolini \& Teles (2010), Cruz (2010), entre outros). Ferreira \& Araújo (2006) expõem que um aumento de $10 \%$ no estoque de infraestrutura pública geraria um aumento de 3,3\% do PIB per capita brasileiro no longo-prazo. Ferreira \& Malliagros (1998) e Mussolini \& Teles (2010) encontraram uma relação de longo-prazo positiva entre a infraestrutura e a PTF. De acordo com Mussolini \& Teles (2010), um aumento de $10 \%$ na relação capital público-privado aumenta em $24 \%$ a PTF no longo prazo. Além disso, os autores mostram que aumentos na infraestrutura, para um dado estoque de capital privado, causam no sentido de Granger a PTF.

Apesar de os estudos nacionais indicarem efeitos positivos entre a infraestrutura e a atividade econômica, em nível regional os estudos não encontraram evidências empíricas sistemáticas. Os artigos sugerem que o efeito da infraestrutura sobre o desenvolvimento regional brasileiro é ambíguo e, em alguns casos, é encontrado efeito adverso.

Andrade \& Serra (1999) sugerem que o efeito da infraestrutura sobre o crescimento das cidades médias brasileiras apresentou reversão de sinal ao longo do período analisado (1970 a 1990). Azzoni et al. (2000) investigaram os efeitos do acesso à coleta de esgoto, à eletricidade e à coleta de lixo sobre o crescimento da renda dos estados brasileiros ao longo do período de 1981 a 1996. Nos modelos estimados, a única variável de infraestrutura que se mostrou significativa foi a coleta de lixo, e em todos os casos, seu coeficiente estimado foi positivo. Chagas \& Toneto Júnior (2003) sugerem que, a princípio, a infraestrutura previamente existente desempenhou um papel negativo sobre a taxa de crescimento dos municípios brasileiros. No entanto, há um ponto de mínimo, a partir do qual ocorre uma inversão e a infraestrutura passa a ter um impacto positivo sobre o crescimento.

Esses resultados divergem daqueles encontrados nos estudos nacionais e nos estudos regionais realizados em outros países. Dada essa discrepância, este artigo busca aprofundar a análise da relação empírica entre a dotação de infraestrutura e o crescimento dos municípios brasileiros. Para isto, generalizase o modelo teórico de crescimento econômico regional desenvolvido por Glaeser et al. (1995), incorporando o capital público na função de produção das

diversas críticas com relação à abordagem econométrica. Em linhas gerais, os estudos empíricos evoluíram na perspectiva de superar os problemas econométricos que envolvem a estimação da relação causal entre infraestrutura e produto ou crescimento. As três principais preocupações da literatura empírica sobre os impactos da infraestrutura são: medida, identificação e heterogeneidade (ver Calderón \& Servén (2014)). 
firmas. Para estimar o modelo teórico reconhece-se que os municípios estão sujeitos a diversas formas de interação espacial. Assim, optou-se por um método econométrico capaz de acomodar tanto a heterogeneidade quanto a dependência espacial entre os municípios.

O artigo está dividido em três seções, além da introdução e das considerações finais. Na próxima é desenvolvido o modelo teórico. A seção seguinte apresenta a metodologia econométrica utilizada e, por fim, são apresentados e debatidos os resultados.

\section{Modelo}

O modelo desenvolvido nesta seção para analisar a relação entre a infraestrutura pública e o crescimento local é uma extensão do modelo de Glaeser et al. (1995). Incorpora-se ao modelo a presença de um governo local, cuja única função é o provimento de infraestrutura (capital) pública. Esta extensão permite que a infraestrutura pública afete a produção local diretamente, bem como afete as decisões de investimento privado das firmas instaladas em determinada região.

Borts (1960) e Borts \& Stein (1964) foram um dos primeiros modelos de crescimento regional a considerar o livre movimento dos fatores de produção entre regiões. De acordo com os autores, o capital se deslocaria para regiões com menor relação capital-trabalho e o trabalho migraria para as regiões nas quais essa relação é maior. Assim, a remuneração de cada fator de produção tenderia a se igualar regionalmente. Todavia, diversos autores perceberam que havia diferenciais de longo prazo dos salários reais entre as regiões, sem nenhuma tendência de equalização.

Com o intuito de estudar a disparidade dos salários regionalmente, Rosen (1979) e Roback (1982) desenvolveram um modelo teórico no qual a livre mobilidade dos fatores criaria um equilíbrio espacial estático. No entanto, esse equilíbrio dependeria da equalização dos níveis de utilidade no espaço. A migração populacional seria a principal responsável por conduzir ao equilíbrio espacial. A principal conclusão empírica dos autores é que os diferenciais regionais nos salários podem ser amplamente explicados pelos atributos locais (nível de qualidade de vida).

Glaeser et al. (1995) desenvolveram um modelo com o objetivo de verificar as forças econômicas responsáveis por explicar o crescimento das cidades. Para tanto, os autores adaptaram o modelo de Barro \& Sala-i-Martin (1992) ao âmbito regional, adotando as hipóteses de Rosen (1979) e Roback (1982) ${ }^{3}$.

De acordo com Glaeser et al. (1995) (p. 118), "as cidades são economias completamente abertas, sem barreiras, com livre mobilidade de capital, trabalho e ideias". Portanto, "diferenças na taxa de crescimento não podem ser justificadas pela taxa de poupança ou dotação exógena de mão de obra" (Glaeser et al. (1995), p. 119). "As cidades irão diferir apenas pelo seu nível de produtividade e qualidade de vida" (Glaeser et al. (1995), p. 119). A principal hipótese assumida pelos autores consiste na consideração de que a renda elevada de determinada cidade possa ser compensada pela baixa qualidade de vida associada a ela, como criminalidade, engarrafamentos, entre outros.

\footnotetext{
${ }^{3} \mathrm{O}$ estudo de Barro e Sala-\&-Martin buscava verificar se existiam forças automáticas que contribuíam para a convergência da renda entre as nações e se países pobres tendiam a crescer mais rápido que países ricos.
} 
Portanto, a livre mobilidade não conduzirá à equalização dos salários entre as regiões, mas conduzirá a um equilíbrio espacial no qual os níveis de utilidade são igualados.

A extensão do modelo de Glaeser et al. (1995) será apresentada a seguir. $\mathrm{O}$ modelo supõe que as firmas produzem um único e similar produto final, utilizando para isso a mesma função de produção. A oferta de trabalho total é fixa, portanto a única forma de uma região empregar mais trabalho será por meio da migração de mão de obra de outras regiões. O mercado é regido por concorrência perfeita e não existe custo de transporte entre as regiões. Assim, o preço dos produtos é regionalmente uniforme.

O produto agregado da cidade $i$ no período $t$ é uma função dos fatores de produção existentes na cidade:

$$
Y_{i, t}=\left(A_{i, t} L_{i, t}\right)^{1-\alpha} K_{i, t}^{\alpha} G_{i, t}^{\beta}
$$

em que, $A_{i, t}$ representa o nível de produtividade da cidade $i$ no período $t$, $L_{i t}$ denota a quantidade de mão de obra disponível na cidade $i$ no instante $t$, $K_{i t}$ é o estoque de capital privado existente na cidade $i$ no período $t$, $G_{i t}$ é o estoque de capital público disponível na cidade $i$ no instante $t^{4}$.

O único papel do governo nessa economia é prover a infraestrutura pública necessária para a produção local. Para isso, ele tributa a remuneração do capital privado. Admite-se que, em todos os períodos, o governo mantenha seu orçamento equilibrado, portanto ele investe toda a sua receita tributária em capital público, $I_{i, t}^{k}(T)=\tau_{i, t} r_{i, t} K_{T}$, em que $T=t-\Delta, \Delta>0$. O estoque de capital público da cidade $i$ no período $t, G_{i, t}$, é fruto da acumulação dos fluxos de investimentos públicos em capital, $I_{i, t}^{k}$, excluída a depreciação do capital ${ }^{5}$.

$$
G_{i, t}(T)=\int_{0}^{\infty}\left(I_{i, t}^{K}(T)-\delta G_{i, t}(T)\right) d T
$$

Sob o regime de concorrência perfeita, o objetivo das firmas da cidade $i$ será a maximização de seu fluxo de lucros intertemporal, o que equivale a maximizar o lucro presente:

$$
\max _{K, L} \pi_{i, t}=\left[f\left(A_{i, t}, K_{i, t}, L_{i, t}, G_{i, t}\right)-w_{i, t} L_{i, t}-\left(r_{i, t}\left(1-\tau_{i, t}\right)+\delta\right) K_{i, t}\right]
$$

Das condições de primeira ordem do problema firmas, conclui-se que os fatores de produção recebem como remuneração a sua produtividade marginal, após o pagamento dos impostos:

$$
\begin{gathered}
w_{i, t}=(1-\alpha) A_{i, t}^{1-\alpha} L_{i, t}^{-\alpha} K_{i, t}^{\alpha} G_{i, t}^{\beta} \\
r_{i, t}=\frac{(1-\alpha)\left(A_{i, t} L_{i, t}\right)^{1-\alpha} K_{i, t}^{\alpha-1} G_{i, t}^{\beta}-\delta}{\left(1-\tau_{i, t}\right)}
\end{gathered}
$$

\footnotetext{
${ }^{4}$ Supõe-se que todo o capital público seja composto de bens de infraestrutura.

${ }^{5}$ Considera-se que o capital público não receba nenhuma compensação, a não ser a receita auferida pelo pagamento dos impostos por parte das firmas, $\tau_{i, t} r_{i, t} K_{i, t}$.
} 
Perante a decisão do local de moradia, além da remuneração do trabalho em cada região, os indivíduos levam em consideração a qualidade de vida regional. Supõe-se que o índice de qualidade de vida regional, $V_{i, t}$, dependa do tamanho populacional, $L_{i, t}$, e dos fatores que afetam a qualidade de vida local, $Q_{i, t}$. Assim como Glaeser et al. (1995), assume-se que o índice de qualidade de vida da cidade $i$ decresce com o tamanho de sua população. A variável $Q_{i, t}$ captura um grande conjunto de fatores que afetam a qualidade de vida nos municípios, como: criminalidade, custo de vida, poluição, congestionamento de trânsito, entre outros.

$$
V_{i, t}=Q_{i, t}\left(L_{i, t}\right)^{-\sigma}
$$

A utilidade total do migrante potencial para a cidade $i$ relaciona o salário recebido pelos trabalhadores nessa cidade com o seu índice de qualidade de vida:

$$
U_{i, t}=w_{i, t} V_{i, t}
$$

A livre mobilidade do trabalho conduzirá ao equilíbrio espacial, no qual o nível de utilidade de todas as regiões se igualará ao nível de utilidade da região média, $U_{t}$. De acordo com a Equação (7), as variáveis que afetam a remuneração do trabalho - PTF, trabalho, capital privado e capital público afetam o nível de utilidade dos moradores da cidade $i$. Assim, ao longo do tempo, os fatores responsáveis pela variação da utilidade da cidade $i$ são a variação da produtividade, a taxa de crescimento do capital privado, da força de trabalho, do capital público e da qualidade de vida.

$$
\begin{aligned}
\ln \left(\frac{U_{t+1}}{U_{t}}\right)= & (1-\alpha) \ln \left(\frac{A_{i, t+1}}{A_{i, t}}\right)+\alpha \ln \left(\frac{K_{i, t+1}}{K_{i, t}}\right)+\beta \ln \left(\frac{G_{i, t+1}}{G_{i, t}}\right) \\
& +\ln \left(\frac{Q_{i, t+1}}{Q_{i, t}}\right)-(\sigma+\alpha) \ln \left(\frac{L_{i, t+1}}{L_{i, t}}\right)
\end{aligned}
$$

As variações na produtividade, no capital privado, no capital público e na qualidade de vida são influenciadas pelas características específicas de cada região e são descritas pelas equações abaixo:

$$
\begin{aligned}
& \ln \left(\frac{A_{i, t+1}}{A_{i, t}}\right)={\overrightarrow{a^{\prime}}}_{i, t} \vec{\gamma}_{A}+\varepsilon_{i, t+1} \\
& \ln \left(\frac{K_{i, t+1}}{K_{i, t}}\right)={\overrightarrow{k^{\prime}}}_{i, t} \vec{\gamma}_{K}+\xi_{i, t+1} \\
& \ln \left(\frac{G_{i, t+1}}{G_{i, t}}\right)={\overrightarrow{g^{\prime}}}_{i, t} \vec{\gamma}_{G}+c_{i, t+1} \\
& \ln \left(\frac{Q_{i, t+1}}{Q_{i, t}}\right)={\overrightarrow{q^{\prime}}}_{i, t} \vec{\gamma}_{Q}+\zeta_{i, t+1}
\end{aligned}
$$


Em que $\vec{a}_{i, t}, \vec{k}_{i, t}, \vec{g}_{i, t}, \vec{q}_{i, t}$ são os vetores de variáveis características da cidade $i$ no instante $t$, que influenciam, respectivamente, o crescimento do nível de produtividade, do estoque de capital privado, do estoque de capital público e da qualidade de vida na região $i$.

$$
\begin{gathered}
\ln \left(\frac{U_{i, t+1}}{U_{i, t}}\right)=(1-\alpha)\left[{\overrightarrow{a^{\prime}}}_{i, t} \vec{\gamma}_{A}+\varepsilon_{i, t+1}\right]+\alpha\left[{\overrightarrow{k^{\prime}}}_{i, t} \vec{\gamma}_{K}+\xi_{i, t+1}\right] \\
+\beta\left[{\overrightarrow{g^{\prime}}}_{i, t} \vec{\gamma}_{G}+\varsigma_{i, t+1}\right]+\left[{\overrightarrow{q^{\prime}}}_{i, t} \vec{\gamma}_{Q}+\zeta_{i, t+1}\right] \\
-(\sigma+\alpha) \ln \left(\frac{L_{i, t+1}}{L_{i, t}}\right)
\end{gathered}
$$

"O crescimento da mão de obra é a maneira mais direta de capturar o quanto os municípios estão crescendo e tornando-se atrativos para a moradia e mercado de trabalho" (Glaeser et al. (1995), p. 121). Dessa forma, resolvendo a Equação (12) para a variação da mão de obra, tem-se:

$$
\ln \left(\frac{L_{i, t+1}}{L_{i, t}}\right)=\left[\begin{array}{l}
\vec{a}_{i, t} \\
\vec{k}_{i, t} \\
\vec{g}_{i, t} \\
\vec{q}_{i, t}
\end{array}\right]^{\prime} \cdot\left[\begin{array}{l}
\vec{\mu} \\
\vec{\chi} \\
\vec{\eta} \\
\vec{\theta}
\end{array}\right] \cdot\left[\begin{array}{llll}
1 & 1 & 1 & 1
\end{array}\right]+\omega_{i, t+1}
$$

Em que:

$$
\begin{array}{r}
\vec{\mu}=\frac{(1-\alpha) \overrightarrow{\gamma_{A}}}{(\sigma+\alpha)}, \vec{\chi}=\frac{\alpha \overrightarrow{\gamma_{K}}}{(\sigma+\alpha)}, \vec{\eta}=\frac{\beta \overrightarrow{\gamma_{G}}}{(\sigma+\alpha)}, \vec{\theta}=\frac{\overrightarrow{\gamma_{Q}}}{(\sigma+\alpha)} \\
e \omega_{i, t+1}=\frac{(1-\alpha)}{(\sigma+\alpha)} \varepsilon_{i, t+1}+\frac{\alpha}{(\sigma+\alpha)} \xi_{i, t+1}+\frac{\beta \zeta_{i, t+1}}{(\sigma+\alpha)} \\
+\frac{\zeta_{i, t+1}}{(\sigma+\alpha)}-\frac{1}{(\sigma+\alpha)} \ln \left(\frac{U_{t+1}}{U_{t}}\right)
\end{array}
$$

A Equação (13) descreve como as variáveis características de cada região afetam o crescimento da mão de obra por meio de seus efeitos sobre o crescimento da produtividade, do capital privado, do capital público e da qualidade de vida. Portanto, os vetores $\vec{\mu}, \vec{\chi}, \vec{\eta}$ e $\vec{\theta}$ mensuram o efeito indireto das características regionais sobre o crescimento da mão de obra. O termo de erro composto e não correlacionado com as variáveis características da cidade $i$ no período t é dado por $\omega_{i, t+1}$.

Conforme já discutido, o crescimento populacional é a melhor medida para analisar o crescimento regional. A variação da renda também pode ser utilizada como medida do crescimento local, mas esta sofre a influência da qualidade de vida local. O crescimento da renda na cidade $i$ neste artigo será representado pela taxa de crescimento dos salários. Uma vez que há a dificuldade em verificar o local de origem da renda do capital, a renda do trabalho torna-se a variável mais adequada para medir a dinâmica da renda dos municípios. 


$$
\begin{aligned}
\ln \left(\frac{w_{i t,+1}}{w_{i, t}}\right)=\alpha & \ln \left(\frac{K_{i t,+1}}{K_{i, t}}\right)+(1-\alpha) \ln \left(\frac{A_{i t,+1}}{A_{i, t}}\right)-\alpha \ln \left(\frac{L_{i t,+1}}{L_{i, t}}\right) \\
& +\beta \ln \left(\frac{G_{i t,+1}}{G_{i, t}}\right)
\end{aligned}
$$

Inserindo (8), (9), (10) e (11) em (14) obtém-se:

$$
\ln \left(\frac{w_{i, t+1}}{w_{i, t}}\right)=\left[\begin{array}{l}
\vec{k}_{i, t} \\
\vec{a}_{i, t} \\
\vec{g}_{i, t} \\
\vec{q}_{i, t}
\end{array}\right]^{\prime} \cdot\left[\begin{array}{c}
\vec{\delta} \\
\vec{\lambda} \\
\vec{\varphi} \\
\vec{\psi}
\end{array}\right] \cdot\left[\begin{array}{llll}
1 & 1 & 1 & 1
\end{array}\right]+v_{i, t+1}
$$

Em que:

$$
\begin{array}{r}
\vec{\delta}=\frac{(\sigma \alpha) \overrightarrow{\gamma_{K}}}{(\alpha+\sigma)}, \vec{\lambda}=\frac{[\sigma(1-\alpha)] \overrightarrow{\gamma_{A}}}{(\alpha+\sigma)}, \vec{\varphi}=\frac{(\sigma \beta) \overrightarrow{\gamma_{G}}}{(\alpha+\sigma)}, \vec{\psi}=-\frac{\alpha \overrightarrow{\gamma_{Q}}}{(\alpha+\sigma)} \\
e v_{i, t+1}=\alpha \xi_{i, t+1}+(1-\alpha) \varepsilon_{i, t+1}+\beta \varsigma_{i, t+1}-\alpha \omega_{i, t+1}
\end{array}
$$

O efeito das variáveis características de cada região sobre o crescimento dos salários pode ser verificado por meio da equação (15). Os vetores de coeficientes $\vec{\delta}, \vec{\lambda}, \vec{\phi}$ e $\vec{\psi}$ mensuram o efeito indireto das variáveis características locais sobre o crescimento dos salários, por meio de seus efeitos sobre crescimento da produtividade, do capital privado, do capital público e da qualidade de vida. O termo de erro composto e não correlacionado com as variáveis características da cidade $i$ no período $t+1$ é dado por $v_{i, t+1}$.

As Equações (13) e (15) relacionam o crescimento populacional e da renda com das características de infraestrutura existente nos municípios. Dessa forma, estas equações são as especificações que serão estimadas por meio da metodologia de econometria espacial.

\section{Metodologia}

Os municípios brasileiros são suscetíveis a diversas formas de interação, portanto é de se esperar que existam efeitos espaciais entre eles. Por essa razão, faz-se necessário a utilização de métodos econométricos que incorporem a influência da configuração espacial, a fim de estimar apropriadamente o impacto das variáveis independentes sobre as variáveis de interesse das regiões. Os efeitos espaciais podem ser separados em dois tipos: dependência espacial e heterogeneidade espacial.

A dependência espacial ocorre em virtude da influência simultânea e multidirecional que as regiões exercem umas sobre as outras. O segundo tipo denominado heterogeneidade espacial, é consequência da ampla evidência da ausência de estabilidade estrutural dos dados espaciais. Isto significa diferentes respostas para distintas regiões, resultando em formas funcionais e parâmetros variantes no espaço.

Neste artigo optou-se pela estimação do modelo de dados espaciais em painel, uma vez que este é capaz de controlar os dois tipos de efeitos espaciais. Os 
modelos de painel de dados espaciais permitem a existência de diversas formas de dependência espacial entre as regiões. Além disso, o modelo permite também a heterogeneidade espacial, por meio da inclusão de uma variável idiossincrática específica de cada região e invariante no tempo ${ }^{6}$. A forma geral do modelo de dados espaciais em painel é dada pela Equação $(16)^{7}$ :

$$
\begin{gathered}
y_{t}=\alpha i_{n}+\mu+\rho W_{1} y_{t}+X_{t} \beta+W_{1} X_{t} \tau+\xi_{t} \\
\xi_{t}=\lambda W_{2} \xi_{t}+\varepsilon_{t}
\end{gathered}
$$

Em que $\mu=\left(\mu_{1}, \ldots, \mu_{N}\right)^{\prime}$ é o vetor composto pelas variáveis idiossincráticas específicas de cada região e invariante no tempo, que afetam a variável dependente, mas são de difícil observação; $y_{t}=\left(y_{1 t}, \ldots, y_{n t}\right)^{\prime}$ é o vetor das variáveis dependentes; $W_{1} y_{t}$ denota o efeito da interação da variável dependente de uma região com a de seus vizinhos; $X_{t}=\left(X_{1 t}^{\prime}, \ldots, X_{n t}^{\prime}\right)^{\prime}$ é a matriz composta pelos vetores empilhados das variáveis explicativas exógenas de cada região; $W_{1} X_{t}=\left(W_{1} X_{1 t}^{\prime}, \ldots, W_{1} X_{n t}^{\prime}\right)^{\prime}$ representa as variáveis explicativas exógenas defasadas espacialmente; $\xi_{t}=\left(\xi_{1 t}, \ldots, \xi_{n t}\right)^{\prime}$ é o vetor empilhado do termo de erro autocorrelacionado espacialmente; $W_{2} \xi_{t}$ representa a defasagem espacial do termo de erro; $\varepsilon_{t}=\left(\varepsilon_{1 t}, \ldots, \varepsilon_{n t}\right)^{\prime}$ é o vetor empilhado dos termos de erro aleatórios independentes e identicamente distribuídos com média zero e variância; $\sigma^{2} I_{n}, \rho$ é o coeficiente autorregressivo espacial; e, $\lambda$ é conhecido como parâmetro de erro autorregressivo espacial. O intercepto $\alpha$ só poderá ser estimado sob a condição de que $\sum_{i} \mu_{i}=0$.

Assim como no modelo de painel convencional, no de dados espaciais em painel também existem duas formas de especificação da variável idiossincrática de cada região. Dessa forma, o modelo de dados espaciais em painel possui duas variantes: o modelo de efeitos fixos e o de efeitos aleatórios. Entretanto, quando se trabalha com toda a população de regiões, o modelo de efeitos aleatórios não é apropriado (Beenstock, Felsenstein, 2006 apud Almeida (2012). Portanto, neste artigo será abordado apenas o modelo de efeitos fixos, uma vez que a base de dados utilizada é composta por toda população de regiões.

O modelo de efeito fixo considera que a variável idiossincrática de cada região é não observável, invariante no tempo e potencialmente correlacionada com as variáveis explicativas ${ }^{8}$. Essa formulação permite que as diferenças não observáveis entre as unidades de interesse sejam capturadas pelos diferentes termos constantes.

Para tratar da endogeneidade entre investimentos em infraestrutura e crescimento, a estratégia de identificação utilizada foi considerar o estoque de infraestrutura instalada no ano inicial para explicar a taxa de crescimento nos próximos dez anos. Assim, busca-se minimizar a questão da causalidade reversa ao considerar como variável explicativa a infraestrutura defasada temporalmente. Não é de se esperar que a taxa de crescimento futura da renda ou da população afete o estoque de infraestrutura previamente instalado. Além

\footnotetext{
${ }^{6} \mathrm{O}$ modelo convencional de dados em painel também é capaz de acomodar a heterogeneidade espacial. Entretanto, o mesmo necessita de adaptação para considerar a existência da dependência espacial entre as observações.

${ }^{7} \mathrm{Na}$ equação (16), os dados estão empilhados por unidade em corte transversal.

${ }^{8}$ Assim, $E\left(\mu_{i} / x_{i t}\right)$ pode ser qualquer função de $x_{i t}$.
} 
disso, não se deve esperar que fatores não observados que afetam o crescimento dos próximos dez anos também afetem os componentes da infraestrutura já instalados.

Os modelos de efeito fixo com diferentes formas de dependência espacial serão apresentados abaixo.

\section{i. Modelo de efeito fixo com defasagem espacial (SAR)}

O modelo de efeito fixo com defasagem espacial da variável dependente assume a seguinte forma:

$$
y_{t}=\mu_{t}+\rho W y_{t}+X_{t} \beta+\xi_{t}
$$

Enquanto em uma regressão linear os parâmetros estimados são interpretados como a derivada parcial da variável dependente com relação a uma variável explicativa, em um modelo com dependência espacial da variável dependente, a interpretação dos coeficientes estimados é mais complexa, uma vez que há spillovers regionais. Conforme Lesage \& Pace (2009), uma mudança em uma variável explicativa de uma região tem efeitos diretos sobre a variável dependente da própria região e potencialmente afeta a variável dependente das outras regiões indiretamente. Assim, modelos que possuem defasagem espacial da variável dependente requerem uma interpretação especial dos parâmetros. O efeito marginal total é a soma dos efeitos marginais diretos e indiretos proporcionados por essas mudanças e pela realimentação que ocorre através das regiões. Como derivado em Lesage \& Pace (2009), para um modelo SAR, o efeito marginal total de uma variável explicativa $k\left(X_{k}\right)$ sobre a variável dependente y é $(1-\rho)^{-1} \beta^{9}$.

Neste artigo, foi utilizado o procedimento de estimação por máxima verossimilhança do modelo de efeitos fixos com defasagem espacial da variável dependente desenvolvido por Elhorst $(2003,2010)$. A função log-verossimilhança, assumindo que os efeitos espaciais são fixos e que há autocorrelação espacial da variável dependente, assume a seguinte forma:

$$
\begin{array}{r}
\log L\left(\mu, \rho, \beta, \sigma^{2}\right)=\frac{-N T}{2} \log \left(2 \pi \sigma^{2}\right)+T \log \left|I_{N}-\rho W\right| \\
-\frac{1}{2 \sigma^{2}} \sum_{i=1}^{N} \sum_{t=1}^{T}\left(y_{i t}-\rho \sum_{j=1}^{N} w_{i j} y_{j t}-x_{i t} \beta-\mu_{i}\right)^{2}
\end{array}
$$

O estimador do efeito espacial não observável, $\hat{\mu}_{i}$, pode ser encontrado a partir da maximização da função log-verossimilhança com respeito à $\mu_{i}$ :

$$
\hat{\mu}_{i}=\frac{1}{T} \sum_{t=1}^{T}\left(y_{i t}-\rho \sum_{j=1}^{N} w_{i j} y_{j t}-\boldsymbol{x}_{\boldsymbol{i} t} \boldsymbol{\beta}\right), i=1, \ldots, N
$$

Substituindo a solução de $\mu_{i}$ na função log-verossimilhança, obtém-se a função de log-verossimilhança concentrada com respeito à $\beta, \rho$ e $\sigma^{2}$ :

\footnotetext{
${ }^{9}$ Ver Lesage \& Pace (2009) e Almeida (2012) para maiores detalhes sobre o método de cálculo dos efeitos marginais diretos e indiretos.
} 


$$
\begin{array}{r}
\log L=\frac{-N T}{2} \log \left(2 \pi \sigma^{2}\right)+T \log \left|I_{N}-\rho W\right|-\frac{1}{2 \sigma^{2}} \\
\sum_{i=1}^{N} \sum_{t=1}^{T}\left(y_{i t}^{*}-\rho\left[\sum_{j=1}^{N} w_{i j} y_{j t}\right]^{*}-x_{i t}^{*} \beta\right)^{2}
\end{array}
$$

Em que as variáveis com asterisco representam o desvio das variáveis originais de suas médias temporais (“demeaned") ${ }^{10}$ :

$$
\begin{gathered}
y_{i t}^{*}=y_{i t}-\frac{1}{T} \sum_{t=1}^{T} y_{i t} \\
\boldsymbol{x}_{\boldsymbol{i} t}^{*}=\boldsymbol{x}_{\boldsymbol{i} t}-\frac{1}{T} \sum_{t=1}^{T} \boldsymbol{x}_{\boldsymbol{i} t} \\
{\left[\sum_{j=1}^{N} w_{i t} y_{j t}\right]^{*}=\sum_{j=1}^{N} w_{i t} y_{j t}-\frac{1}{T} \sum_{t=1}^{T} \sum_{j=1}^{N} w_{i t} y_{j t}}
\end{gathered}
$$

Lee \& Yu (2010) provaram que a abordagem desenvolvida por Elhorst $(2003,2010)$ fornece estimativas inconsistentes do parâmetro de variância se $N$ for grande e $T$ pequeno. Os autores propuseram o seguinte procedimento de correção do viés da variância obtida pela estimação desenvolvida acima.

$$
\hat{\sigma}_{C V}^{2}=\frac{T}{T-1} \hat{\sigma}^{2}
$$

\section{ii. Modelo de efeito fixo com erro autorregressivo espacial (SEM)}

O modelo tradicional de efeitos fixos estendido para incorporar a autocorrelação espacial do termo de erro pode ser especificado como:

$$
\begin{gathered}
y_{t}=\mu+X_{t} \beta+\xi_{t} \\
\xi_{t}=\lambda W_{2} \xi_{t}+\varepsilon_{t}
\end{gathered}
$$

A função de log-verossimilhança desse modelo é dada por:

$$
\begin{aligned}
& \log L\left(\beta, \lambda, \sigma^{2}\right)=\frac{-N T}{2} \log \left(2 \pi \sigma^{2}\right)+T \log \left|I_{N}-\lambda W\right| \\
&-\frac{1}{2 \sigma^{2}} \sum_{i=1}^{N} \sum_{t=1}^{T}\left\{y_{i t}^{*}-\lambda\left[\sum_{j=1}^{N} w_{i j} y_{j t}\right]^{*}-\left(x_{i t}^{*}-\lambda\left[\sum_{j=1}^{N} w_{i j} x_{j t}\right]^{*}\right) \beta\right.
\end{aligned}
$$

\footnotetext{
${ }^{10} \mathrm{~A}$ abordagem descrita equivale ao procedimento de eliminação do efeito espacial fixo antes da estimação por meio da utilização do operador de desvio da média no tempo $(Q=$ $\left.I_{N T}-\frac{1}{T} i_{T} i_{T} \otimes I_{N}\right)$. Esse procedimento possui a vantagem de evitar o problema do parâmetro incidental, e somente poderá ser utilizado se a matriz $Q$ puder ser substituída por sua inversa generalizada. A estimação desse modelo também é realizada por máxima verossimilhança em virtude da endogeneidade remanescente da variável dependente defasada espacialmente. $Q^{+}$é chamada de inversa generalizada (Moore-Penrose) de $Q$ se ela satisfizer as seguintes condições:

1. $Q \times Q^{+} \times Q=Q$

2. $Q^{+} \times Q \times Q^{+}=Q^{+}$

3. $\left(Q^{+} Q\right)^{\prime}=Q^{+} Q$

4. $\left(Q^{+}\right)^{\prime}=Q^{+}$
} 
Dado $\lambda$, o estimador de máxima verossimilhança de $\beta$ e $\sigma^{2}$ pode ser resolvido por meio das condições de primeira ordem:

$$
\begin{gathered}
\hat{\beta}=\left(\left[X^{*}-\lambda\left(I_{T} \otimes W\right) X^{*}\right]^{\prime}\left[X^{*}-\lambda\left(I_{T} \otimes W\right) X^{*}\right]\right)^{-1} \\
{\left[X^{*}-\lambda\left(I_{T} \otimes W\right) X^{*}\right]^{\prime}\left[Y^{*}-\lambda\left(I_{T} \otimes W\right) Y^{*}\right]} \\
\widehat{\sigma^{2}}=\frac{\epsilon(\lambda)^{\prime} \epsilon(\lambda)}{N T}
\end{gathered}
$$

Em que $\varepsilon(\lambda)=Y^{*}-\lambda\left(I_{T} \otimes W\right) Y^{*}-\left[X^{*}-\lambda\left(I_{T} \otimes W\right) X^{*}\right] \beta$.

A função log-verossimilhança concentrada em $\lambda$ é descrita pela Equação (26), dado $\beta$ e $\sigma^{2}$. A condição de primeira ordem com relação a $\lambda$ fornece o estimador desse parâmetro.

$$
\log L(\lambda)=\frac{-N T}{2} \log \left[\epsilon(\lambda)^{\prime} \epsilon(\lambda)\right]+T \log \left|I_{N}-\lambda W\right|
$$

Para estimar ambos os parâmetros, pode-se utilizar um procedimento iterativo, no qual o conjunto de parâmetros $\beta$ e $\sigma^{2}$ e o parâmetro $\lambda$ são estimados alternativamente até a convergência ocorrer.

\section{Base de Dados}

A base de dados utilizada neste artigo foi extraída dos Censos Demográficos de 1970, 1980, 1991, 2000 e 2010, realizados pelo Instituto Brasileiro de Geografia e Estatística (IBGE). Durante estas quatro décadas houve um forte processo de emancipação dos distritos, desmembrando-se de um ou mais municípios. A Tabela 1 mostra a quantidade de municípios por região geográfica ao longo do tempo.

A criação de novos municípios gera uma complexa dificuldade aos estudos com dados longitudinais em nível municipal. Em geral, existem algumas formas amplamente utilizadas na literatura para lidar com esse problema: i) considerar apenas os municípios existentes no período inicial, desconsiderandose aqueles que se originaram a partir destes; ii) acompanhar apenas os municípios que não sofreram perda territorial ao longo do tempo do estudo; iii) agregar os municípios por área mínima de comparação (AMC), de forma que as áreas sejam as mesmas ao longo do tempo. A metodologia de AMC foi adotada neste artigo para contornar o problema das emancipações. A opção pela utilização de AMC deve-se ao fato de ser a forma mais utilizada na literatura, tornando os resultados deste estudo mais comparáveis.

Como proxies para a variável de infraestrutura instalada foram utilizados o percentual de domicílios com acesso aos serviços básicos de infraestrutura. Mais especificamente, calculou-se o percentual de domicílios com acesso a abastecimento de água pela rede geral de distribuição, a coleta de esgoto pela rede geral e a energia elétrica fornecida pela companhia distribuidora em cada AMC.

Conforme discutido na seção anterior, as variáveis dependentes do modelo são o crescimento populacional e o crescimento do salário real ao longo do tempo. A variação populacional foi calculada a partir da quantidade de 
Tabela 1: Distribuição dos municípios brasileiros e AMC por região geográfica

\begin{tabular}{l|r|r|r|r|r|r}
\hline Ano / Região & $\mathbf{1 9 7 0}$ & $\mathbf{1 9 8 0}$ & $\mathbf{1 9 9 1}$ & $\mathbf{2 0 0 0}$ & $\mathbf{2 0 1 0}$ & $\begin{array}{c}\text { AMC } \\
\mathbf{1 9 7 0 - 2 0 1 0}\end{array}$ \\
\hline Brasil & 3.952 & 3.991 & 4.491 & 5.507 & 5.565 & 3.652 \\
Região Norte & 195 & 203 & 298 & 449 & 449 & 143 \\
Região Nordeste & 1.376 & 1.375 & 1.509 & 1.787 & 1.794 & 1.298 \\
Região Sudeste & 1.410 & 1.410 & 1.432 & 1.666 & 1.668 & 1.401 \\
Região Sul & 717 & 719 & 873 & 1.159 & 1.188 & 588 \\
Região Centro-Oeste & 254 & 284 & 379 & 446 & 466 & 222 \\
\hline
\end{tabular}

Fonte: IBGE.

Nota: Os municípios que pertenciam ao estado de Goiás, em 1970 e 1980, e passaram a pertencer a Tocantins, a partir de 1988, estão contabilizados nessa tabela como pertencendo a Região Norte em todos os períodos.

pessoas residentes em cada AMC para cada um dos censos utilizados. Para a mensuração do crescimento do salário per capita foram utilizados os rendimentos das pessoas que possuíam vínculo empregatício com ou sem carteira assinada em sua ocupação principal. Esta opção deve-se ao fato de o trabalhador ser mais propício a trabalhar no local em que reside, do que os lucros serem oriundos do local de residência do detentor do capital.

$\mathrm{O}$ acesso aos serviços de infraestrutura destacados tende a afetar positivamente a produtividade e o produto municipal por diversos canais. Em primeiro lugar, deve-se notar que a oferta desses serviços é condição prévia para o desenvolvimento de diversas atividades econômicas. Disponibilidade de água potável, coleta e tratamento de esgoto e acesso a energia elétrica são indispensáveis para diversas atividades industriais, comerciais e de prestação de serviços. Assim, o investimento em vários setores e a possibilidade de uma maior densidade econômica depende do acesso a esses serviços. Com isso, a definição do local dos investimentos pelas empresas passa pela avaliação da qualidade da infraestrutura disponível.

Além desses efeitos diretos pode-se mencionar outros canais pelos quais a infraestrutura afeta o desempenho econômico. Os serviços de saneamento básico (água e esgoto), por exemplo, geram elevadas externalidades sobre a saúde e o meio ambiente. Quanto maior o acesso a esses serviços, menor tende a ser a incidência de doenças com impactos sobre a produtividade e a geração de renda. Inicialmente pode-se falar da possibilidade de menores despesas com saúde em função do menor volume de internações e gastos com medicamentos, além da menor taxa de mortalidade. Um efeito indireto fortemente destacado pela melhoria das condições de saúde é a melhora dos indicadores educacionais: mais frequência, menos evasão, melhor desempenho escolar, maiores taxas de aprovação, entre outros. Esses efeitos tendem a ampliar o capital humano e a produtividade local. Em termos de geração de renda, pode-se destacar os menores índices de absenteísmo que possibilitam um maior número de horas trabalhadas. E quanto ao meio ambiente, além de impedir os impactos nocivos decorrentes da deterioração ambiental - contaminação dos solos, qualidade dos rios etc. -, viabiliza e estimula um conjunto de atividades econômicas, tais como o turismo, a pesca, entre outras.

$\mathrm{O}$ acesso a energia elétrica também afeta a produtividade por diversos mecanismos. Além de alguns canais semelhantes ao caso do saneamento pode-se 
acrescentar a viabilização de acesso a eletrodomésticos, equipamentos eletrônicos e outros itens que facilitam a comunicação e a informação, além de profundos ganhos econômicos, como a redução de tempo em serviços domésticos, redução de perdas materiais, entre outros. Percebe-se que os itens selecionados como proxy para infraestrutura podem levar a ganhos significativos de produto e produtividade, por diferentes mecanismos. Deve haver uma relação positiva e significativa entre o acesso a esses serviços e o crescimento econômico municipal, seja em termos populacionais ou de produtividade (salário per capita).

A análise dos dados permite verificar que a evolução dos componentes de infraestrutura ao longo do período em estudo foi heterogênea, como pode ser observado na Figura 1. Mesmo os índices de abastecimento de água e coleta de esgoto, que possuíam patamares muito baixos em 1970, apresentaram trajetórias de expansão distintas. O índice de abastecimento de água apresentou taxas de crescimento crescentes até o início da década 1990 (censo de 1991). Entretanto, a partir do censo do ano de 2000, o aumento da cobertura de abastecimento de água pela rede geral passou a crescer a taxas muito inferiores.

Das variáveis de acesso a infraestrutura utilizadas nesse artigo, a coleta de esgoto é a que possui menor indicador de acesso. Em 2010, apenas 54\% dos domicílios brasileiros possuíam acesso a coleta de esgoto. Com relação à evolução do acesso a coleta de esgoto ao longo do período analisado, percebese que houve forte crescimento apenas no censo do ano de 1980, passando a crescer a taxas inferiores desde então.

Desde o início do período analisado, o acesso à energia elétrica foi o componente de infraestrutura com maior cobertura, mas apresentou taxas decrescentes de expansão ao longo do período analisado. O motivo para esse crescimento lento deve-se ao fato de que $85 \%$ dos domicílios brasileiros já possuíam acesso à energia elétrica em 1991.

Figura 1: Evolução do acesso à infraestrutura

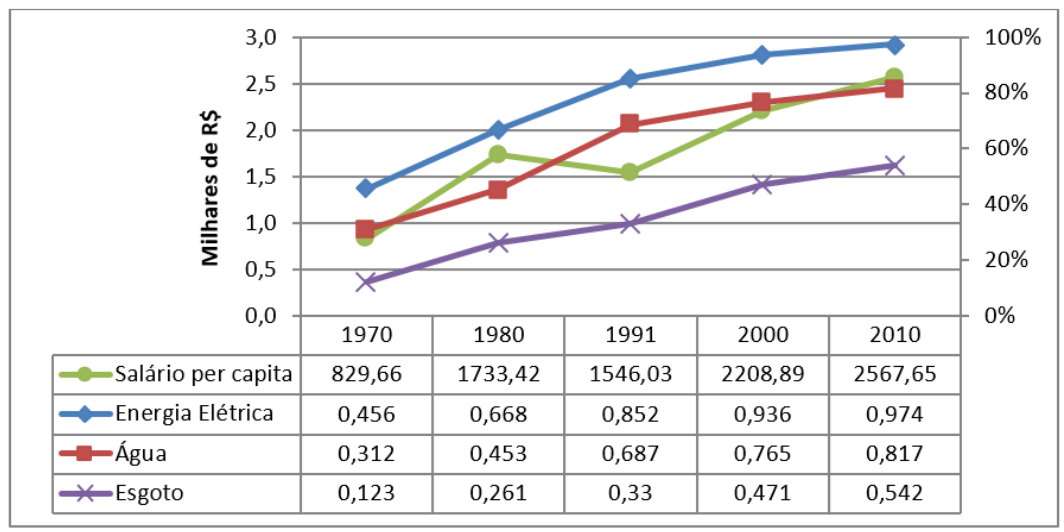

Fonte: Elaborada pelos autores.

Com relação ao perfil regional, ao longo das quatro décadas analisadas, todas as unidades da Federação apresentaram ampliação da cobertura de abastecimento de água, coleta de esgoto e energia elétrica. A evolução espacial das proxies da infraestrutura sugere que o eixo do crescimento do acesso à infraestrutura foi das regiões Sudeste e Sul para as regiões do Centro-Oeste, Norte e 
Nordeste (Apêndice A).

O aumento da cobertura estadual de abastecimento de água e energia elétrica foi acompanhado, em um primeiro estágio, por um aumento das disparidades de acesso entre os municípios. Essa disparidade se reduziu ao longo do tempo, indicando que o crescimento do acesso a esses componentes de infraestrutura atingiu certa maturidade e as desigualdades entre os municípios diminuíram.

Com relação à coleta de esgoto, esse foi o componente da infraestrutura que menos evoluiu no período analisado. Em 2010, nove estados, localizados principalmente nas regiões Norte, Nordeste e Centro-Oeste, encontravam-se abaixo dos $20 \%$ dos domicílios com acesso à coleta de esgoto. O desvio-padrão do acesso à coleta de esgoto entre os municípios se elevou consideravelmente durante todo o período, indicando um crescimento desigual.

\section{Testes de Diagnóstico}

\subsection{Teste de Autocorrelação Espacial}

O teste $I$ de Moran verifica se as observações são espacialmente aleatórias, isto é, se os valores de uma variável em uma região não dependem dos valores desta variável nas regiões vizinhas. Para isso, calcula-se o coeficiente de correlação espacial, para verificar se os dados estão ordenados de acordo com alguma sequência espacial.

Para todas as variáveis estudadas neste artigo, pode-se rejeitar, ao nível de significância de 5\%, a hipótese de que os dados apresentam aleatoriedade espacial ${ }^{11}$. Segundo o teste $I$ de Moran, há uma indicação de autocorrelação positiva das variáveis. Assim, altos (baixos) valores da variável de interesse são circundados por altos (baixos) valores das variáveis de interesse de seus vizinhos.

\subsection{Testes de Especificação}

Teste de Modelos de Dados em Painel

O teste $F$ pode ser usado para verificar se o efeito fixo de cada município é estatisticamente igual a zero. Dessa forma, ele foi utilizado com o objetivo de verificar se o modelo Pooled descreve melhor os dados do que o modelo de efeitos fixos. Os resultados permitem rejeitar, a 1\% de significância, a hipótese nula de que os efeitos idiossincráticos de cada região são nulos. Portanto, o teste $F$ indica que o modelo de efeitos fixos deve ser utilizado, quando comparado com o Pooled.

\section{Testes de Especificação da Dependência Espacial}

Como os dados não são aleatórios espacialmente, torna-se necessário verificar o tipo de interação espacial que os dados apresentam.

\section{Teste Multiplicador de Lagrange (LM)}

O Teste LM é utilizado para verificar se os modelos de defasagem espacial da variável dependente (SAR) ou de erro espacial (SEM) são mais apropriados

\footnotetext{
${ }^{11}$ Todos os Is calculados foram superiores aos Is esperados, cujo valor é -0,00027.
} 
para descrever os dados do que um modelo sem interação espacial. Entretanto, o Teste LM não apresenta muito poder, conduzindo a rejeição da hipótese nula com muita frequência. Para contornar o problema foi desenvolvido o Teste LM robusto, que incorpora um fator de correção que considera a má especificação do modelo (FLORAX et al., 2003 apud Almeida (2012)).

Como apresentado na Tabela 2, os resultados dos testes permitem rejeitar, a 1\% de significância, a hipótese de que um modelo sem dependência espacial é mais apropriado que um modelo SAR ou SEM. O teste LM robusto permite rejeitar, a 5\% de significância, as hipóteses de ausência de dependência espacial da variável dependente e do termo de erro. Além disso, os resultados dos testes sugerem que o modelo de dependência espacial do termo de erro (SEM) é o mais apropriado quando a variável dependente é o crescimento do salário per capita. No entanto, quando a variável dependente é a taxa de crescimento populacional, o modelo mais apropriado é o de dependência espacial da variável dependente (SAR).

Tabela 2: Teste de especificação da dependência espacial

\begin{tabular}{l|c|c}
\hline Variável Dependente & $\begin{array}{c}\text { Crescimento do } \\
\text { Salário per capita } \\
\text { EFEITO FIXO }\end{array}$ & $\begin{array}{c}\text { Crescimento } \\
\text { Populacional } \\
\text { EFEITO FIXO }\end{array}$ \\
\hline LModelo & 441,28 & 1350,17 \\
& $(0,000)$ & $(0,000)$ \\
LM no Spatial lag & 21553,05 & 1348,22 \\
& $(0,000)$ & $(0,000)$ \\
Robust LM no Satial lag & 53,24 & 5,10 \\
& $(0,013)$ & $(0,024)$ \\
Robust LM no Spatial Error & 21111,76 & 3,15 \\
& $(0,000)$ & $(0,076)$ \\
\hline
\end{tabular}

Fonte: Elaborado pelos autores.

\section{Fatores de Inflação da Variância}

A presença de multicolinearidade entre as variáveis pode conduzir a estimativas imprecisas em virtude da grande variância. Assim, a razão $t$ tende a ser estatisticamente insignificante e podem ocorrer reversões de sinais.

A análise preliminar da correlação entre as variáveis indica uma forte correlação entre o acesso ao abastecimento de água e à energia elétrica, superior a 0,8 . Um teste bastante sugerido na literatura para verificar se há o problema da multicolinearidade entre as variáveis é o de fatores de inflação da variância (VIF). O VIF é uma medida do grau em que cada variável independente é explicada pelas demais variáveis explicativas. Rogerson (2001) e Gareth (2013) sugerem que valores do VIF maiores que 5 indicam um potencial problema de multicolinearidade ${ }^{12}$. Conforme apresentado na Tabela 3, os resultados do teste VIF sugerem que a variável água e energia elétrica são fortemente colineares.

Muitos são os métodos sugeridos para resolver o problema da multicolinearidade. Neste artigo, optou-se pelo método da exclusão de uma ou mais variáveis independentes altamente correlacionadas com a variável colinear. Uma

\footnotetext{
${ }^{12}$ Conforme ressaltado por Hair JR (2005) (p.167), "cada pesquisador deve determinar o grau de colinearidade aceitável, pois a maioria dos padrões ou valores recomendados ainda permite uma colinearidade substancial."
} 
Tabela 3: Teste de fatores de inflação da variância

\begin{tabular}{l|c|c}
\hline Variável & VIF & 1/VIF \\
\hline Água & 6,43 & 0,1554 \\
Esgoto & 2,02 & 0,4952 \\
Energia Elétrica & 5,37 & 0,1862 \\
Taxa de Urbanização & 3,46 & 0,2889 \\
Educação & 3,37 & 0,2966 \\
População Inicial & 1,20 & 0,8321 \\
Salário per capita Inicial & 1,02 & 0,9826 \\
\hline
\end{tabular}

Fonte: Elaborada pelos autores.

vez que as variáveis água e energia elétrica são fortemente correlacionadas, estas foram estimadas separadamente.

\section{Resultados}

Nesta seção, serão apresentados e discutidos os resultados obtidos considerando o crescimento populacional e o crescimento do salário per capita como variável para mensuração do crescimento econômico regional.

Antes de apresentar os resultados, é necessário discutir as variáveis que foram utilizadas como controle na estimação. Os resultados encontrados por Glaeser et al. (1995) sugerem que o nível de educação inicial das cidades é o principal determinante do crescimento econômico. Portanto, optou-se por utilizar uma variável educacional para controlar os efeitos dos diferentes níveis de educação sobre o crescimento econômico regional. A variável educacional utilizada neste artigo foi o percentual de pessoas com ensino médio completo, superior completo e incompleto, especialização, mestrado e doutorado, doravante denominada de variável "educação"13.

De acordo com Andrade \& Serra (1999), é importante considerar a taxa de urbanização como variável de controle na estimação. Conforme mostrado pelos autores, no período de 1970 a 1990, o crescimento da população ocupada e do rendimento total foi diferente entre os subgrupos das cidades brasileiras mais urbanizadas e as menos urbanizadas. Ademais, é provável que a urbanização do munícipio possua efeitos sobre crescimento econômico e sobre o estoque de infraestrutura instalada.

\subsection{Crescimento Populacional}

De acordo com os testes realizados na seção anterior, verificou-se que quando a variável dependente é o crescimento populacional, o modelo que melhor descreve os dados é o SAR. Este modelo incorpora a dependência espacial do crescimento populacional. Além disso, o teste de fatores de inflação de

\footnotetext{
${ }^{13}$ Essa proxy é similar a utilizada por Andrade \& Serra (1999) e Chagas \& Toneto Júnior (2003). Dessa forma, é possível uma maior comparabilidade entre os estudos sobre crescimento regional no Brasil. Além disso, há uma impossibilidade técnica para calcular os anos de estudo da população. Nos censos de 1970 e 1980 não há informação sobre anos de estudos das pessoas. Como o regime educacional no Brasil passou por diversas reformas entre os anos 1970 a 2010, não é possível calcular os anos de estudos das pessoas.
} 
variância detectou que as variáveis água e energia elétrica são multicolineares. Portanto, os modelos foram estimados com essas variáveis separadamente.

Como pode ser observado na Tabela 4 , há reversão do sinal dos efeitos direto, indireto e total do acesso ao abastecimento de água ao longo dos modelos, quando variáveis de controle são inseridas na estimação. Portanto, não é possível concluir nada a respeito do efeito do acesso ao abastecimento de água sobre a taxa de crescimento populacional.

O impacto do acesso à energia elétrica sobre a taxa de crescimento populacional só é significativo no modelo (4), no qual nenhuma variável de controle foi inserida. Os resultados indicam que um aumento no acesso à energia elétrica contribui positivamente para o crescimento populacional da própria região.

Todas as outras variáveis se mantiveram estáveis ao longo dos modelos. Em especial, pode-se concluir que a ampliação da cobertura da rede de coleta de esgoto possui efeitos positivos sobre o crescimento populacional no intervalo de 0,008 a 0,04 . Grande parte do efeito positivo dá-se dentro da própria região, uma vez que o efeito médio direto se encontra no intervalo de 0,03 a 0,07 , enquanto o efeito médio indireto é de 0,01 . Os resultados mostram também que as variáveis de controle urbanização e educação possuem impactos positivos sobre o crescimento populacional das regiões. Além disso, pode-se concluir que quanto maior a região, menor será o seu crescimento populacional e o das regiões vizinhas.

\subsection{Crescimento do Salário Real per capita}

Quando a variável utilizada para mensurar o crescimento econômico regional é o crescimento do salário per capita, o modelo SEM foi o que melhor se adequou aos dados. Os resultados estimados segundo esse método apresentaram grande estabilidade ao longo dos modelos estimados.

Os resultados sugerem que o acesso ao abastecimento de água apresenta impactos positivos sobre o crescimento do salário per capita regional. Esse resultado se mantém ao longo dos modelos, ao contrário do resultado ambíguo estimado quando a variável dependente é o crescimento populacional. Os resultados evidenciam também o forte efeito significativo e positivo do acesso à energia elétrica sobre o crescimento salarial, no intervalo de 0,65 a 0,68.

$\mathrm{O}$ acesso à coleta de esgoto mostrou-se, na maioria dos modelos, não significativo. Apenas quando a variável educação é utilizada como variável de controle, o acesso à coleta de esgoto torna-se significativo e negativo. Portanto, de acordo com os resultados, uma ampliação da cobertura da rede de esgoto possui efeitos adversos sobre o crescimento do salário per capita.

Deve-se ressaltar que a utilização da variação salário possui a desvantagem de captar variações na qualidade de vida regional. Firmas localizadas em regiões com baixa qualidade de vida tendem a oferecer salários maiores aos seus empregados como forma de compensação, incentivando assim a migração para essas regiões. Conforme já discutido, o acesso à coleta de esgoto possui grandes efeitos em termos de qualidade de vida, por exemplo, a redução de doença. Portanto, é de se esperar que firmas localizadas em regiões com alta cobertura de coleta de esgoto ofertem salários menores aos seus empregados. Nesse sentido, um aumento da cobertura de acesso à coleta de esgoto tenderia a reduzir o salário per capita, como sugere os nossos resultados. 
Tabela 4: Resultados do impacto da infraestrutura sobre o crescimento populacional

\begin{tabular}{|c|c|c|c|c|c|c|c|}
\hline \multicolumn{8}{|c|}{ Modelo SAR } \\
\hline \multicolumn{2}{|l|}{ Variável / Modelo } & (1) & (2) & (3) & (4) & (5) & (6) \\
\hline \multicolumn{2}{|l|}{ Água } & $\begin{array}{l}0,12^{* * *} \\
(21,189)\end{array}$ & $\begin{array}{c}-0,0013 \\
(-0,157)\end{array}$ & $\begin{array}{c}-0,02^{* * *} \\
(-2,764)\end{array}$ & & & \\
\hline \multicolumn{2}{|l|}{ Esgoto } & $\begin{array}{l}0,06^{* * *} \\
(7,9999)\end{array}$ & $\begin{array}{l}0,03^{* * *} \\
(4,2406)\end{array}$ & $\begin{array}{l}0,0116 \\
(1,4605)\end{array}$ & $\begin{array}{l}0,07^{* * *} \\
(9,2092)\end{array}$ & $\begin{array}{l}0,03^{* * *} \\
(4,3043)\end{array}$ & $\begin{array}{l}0,0102 \\
(1,2837)\end{array}$ \\
\hline \multicolumn{2}{|l|}{ Energia Elétrica } & & & & $\begin{array}{l}0,1^{* * *} \\
(2,879)\end{array}$ & $\begin{array}{l}-0,0005 \\
(-0,08)\end{array}$ & $\begin{array}{r}-0,0109 \\
(-1,58)\end{array}$ \\
\hline \multicolumn{2}{|c|}{ Taxa de Urbanização } & & $0,26^{* * *}$ & $0,24^{* * *}$ & & $0,26^{* * *}$ & $0,23^{* * *}$ \\
\hline \multicolumn{2}{|l|}{ Educação } & & & $\begin{array}{l}(10,26) \\
0,26^{* * *} \\
(6,6058)\end{array}$ & & & $0,24^{* * *}$ \\
\hline \multicolumn{2}{|c|}{ ln da População Inicial } & $\begin{array}{c}-0,39^{* * *} \\
(-85,94)\end{array}$ & $\begin{array}{c}-0,39^{* * *} \\
(-91,79)\end{array}$ & $\begin{array}{c}-0,39^{* * *} \\
(-87,24)\end{array}$ & $\begin{array}{c}-0,38^{* * *} \\
(-91,12)\end{array}$ & $\begin{array}{c}-0,39^{* * *} \\
(-93,49)\end{array}$ & $\begin{array}{c}-0,39^{* * *} \\
(-92,37)\end{array}$ \\
\hline \multicolumn{2}{|l|}{$\mathrm{W}^{*}$ dep.var. } & $\begin{array}{l}0,19^{* * *} \\
(17,20)\end{array}$ & $\begin{array}{l}0,19^{* * *} \\
(26,59)\end{array}$ & $\begin{array}{l}0,19^{* * *} \\
(17,45)\end{array}$ & $\begin{array}{l}0,19^{* * *} \\
(26,51)\end{array}$ & $\begin{array}{l}0,19^{* * *} \\
(26,58)\end{array}$ & $\begin{array}{l}0,19^{* * *} \\
(26,51)\end{array}$ \\
\hline \multirow{3}{*}{ Água } & Efeito Direto & $\begin{array}{c}0,12^{* * *} \\
(20,66)\end{array}$ & $\begin{array}{c}-0,0015 \\
(-0,177)\end{array}$ & $\begin{array}{c}-0,03^{* * *} \\
(-2,88)\end{array}$ & & & \\
\hline & Efeito Indireto & $\begin{array}{l}0,03^{* * *} \\
(11.70)\end{array}$ & $\begin{array}{l}-0,0003 \\
(-0,181)\end{array}$ & $\begin{array}{l}-0,01^{* * *} \\
(-2,811)\end{array}$ & & & \\
\hline & Efeito Total & $\begin{array}{l}0,14^{* * *} \\
(19,84)\end{array}$ & $\begin{array}{c}-0,0018 \\
(-0,178)\end{array}$ & $\begin{array}{c}-0,03^{* * *} \\
(-2,877)\end{array}$ & & & \\
\hline \multirow{3}{*}{ Esgoto } & Efeito Direto & $\begin{array}{l}0,06^{* * *} \\
(8,0922)\end{array}$ & $\begin{array}{l}0,03^{* * *} \\
(4,1022)\end{array}$ & $\begin{array}{c}0,012 \\
(1,5212)\end{array}$ & $\begin{array}{l}0,07^{* * *} \\
(9,5147)\end{array}$ & $\begin{array}{l}0,03^{* * *} \\
(4,368)\end{array}$ & $\begin{array}{l}0,0102 \\
(1,2729)\end{array}$ \\
\hline & Efeito Indireto & $\begin{array}{l}0,01^{* * *} \\
(7,3008)\end{array}$ & $\begin{array}{l}0,01^{* * *} \\
(4,0006)\end{array}$ & $\begin{array}{l}0,0027 \\
(1,5124)\end{array}$ & $\begin{array}{l}0,00^{* * *} \\
(8,6707)\end{array}$ & $\begin{array}{l}0,01^{* * *} \\
(4,2224)\end{array}$ & $\begin{array}{l}0,0023 \\
(1,2696)\end{array}$ \\
\hline & Efeito Total & $\begin{array}{l}0,07^{* * *} \\
(8,1124)\end{array}$ & $\begin{array}{l}0,04^{* * *} \\
(4,0941)\end{array}$ & $\begin{array}{l}0,0146 \\
(1,5214)\end{array}$ & $\begin{array}{l}0,08^{* * *} \\
(9,4741)\end{array}$ & $\begin{array}{l}0,04^{* * *} \\
(4,3545)\end{array}$ & $\begin{array}{l}0,0126 \\
(1,2728)\end{array}$ \\
\hline \multirow{4}{*}{ Energia Elétrica } & Efeito Direto & & & & $0,1^{* * *}$ & $-0,0005$ & $-0,0107$ \\
\hline & Efeito Indireto & & & & $\begin{array}{l}(24,33) \\
0,02^{* * *}\end{array}$ & $\begin{array}{c}(-0,07) \\
-0,0001\end{array}$ & $\begin{array}{c}(-1,55) \\
-0,0024\end{array}$ \\
\hline & Efeito Total & & & & $\begin{array}{l}(16,56) \\
0,12^{* * *}\end{array}$ & $\begin{array}{c}(-0,07) \\
-0,0006\end{array}$ & $\begin{array}{c}(-1,55) \\
-0,0131\end{array}$ \\
\hline & & & & & $(24,04)$ & $(-0,07)$ & $(-1,55)$ \\
\hline
\end{tabular}

Fonte: Elaborada pelos autores. 
Tabela 4: Resultados do impacto da infraestrutura sobre o crescimento populacional (continuação)

\begin{tabular}{|c|c|c|c|c|c|c|c|}
\hline \multicolumn{8}{|c|}{ Modelo SAR } \\
\hline Variável / Modelo & & (1) & (2) & (3) & (4) & (5) & (6) \\
\hline Taxa de Urbanização & $\begin{array}{c}\text { Efeito Direto } \\
\text { Efeito Indireto } \\
\text { Efeito Total }\end{array}$ & & $\begin{array}{c}0,26^{* * *} \\
(19,99) \\
0,06^{* * *} \\
(14,13) \\
0,32^{* * *} \\
(19,4)\end{array}$ & $\begin{array}{l}0,24^{* * *} \\
(18,07) \\
0,05^{* * *} \\
(11,54) \\
0,29^{* * *} \\
(17,68)\end{array}$ & & $\begin{array}{l}0,26^{* * *} \\
(18,05) \\
0,06^{* * *} \\
(13,47) \\
0,31^{* * *} \\
(17,72)\end{array}$ & $\begin{array}{l}0,24^{* * *} \\
(15,44) \\
0,05^{* * *} \\
(12,62) \\
0,29^{* * *} \\
(15,33)\end{array}$ \\
\hline Educação & $\begin{array}{c}\text { Efeito Direto } \\
\text { Efeito Indireto } \\
\text { Efeito Total }\end{array}$ & & & $\begin{array}{l}0,27^{* * *} \\
(6,6601) \\
0,06^{* * *} \\
(6,0041) \\
0,32^{* * *} \\
(6,6227)\end{array}$ & & & $\begin{array}{l}0,24^{* * *} \\
(6,0471) \\
0,05^{* * *} \\
(5,7766) \\
0,29^{* * *} \\
(6,0301)\end{array}$ \\
\hline In da População Inicial & $\begin{array}{c}\text { Efeito Direto } \\
\text { Efeito Indireto } \\
\text { Efeito Total }\end{array}$ & $\begin{array}{c}-0,39^{* * *} \\
(-85,29) \\
-0,09^{* * *} \\
(-14,75) \\
-0,48^{* * *} \\
(-63,50)\end{array}$ & $\begin{array}{l}-0,39^{* * *} \\
(-90,32) \\
-0,09^{* * *} \\
(-20,30) \\
-0,48^{* * *} \\
(-64,85)\end{array}$ & $\begin{array}{c}-0,4^{* * *} \\
(-87,63) \\
-0,09^{* * *} \\
(-15,26) \\
-0,48^{* * *} \\
(-67,81)\end{array}$ & $\begin{array}{c}-0,38^{* * *} \\
(-91,33) \\
-0,09^{* * *} \\
(-20,25) \\
-0,47^{* * *} \\
(-66,09)\end{array}$ & $\begin{array}{l}-0,39^{* * *} \\
(-93,41) \\
-0,09^{* * *} \\
(-19,68) \\
-0,48^{* * *} \\
(-64,97)\end{array}$ & $\begin{array}{l}-0,4^{* * *} \\
(-89,96) \\
-0,09^{* * *} \\
(-20,11) \\
-0,49^{* * *} \\
(-64,94)\end{array}$ \\
\hline $\begin{array}{l}\sigma^{2} \\
\mathbf{R}^{2} \\
\log \mathrm{L}\end{array}$ & & $\begin{array}{c}0,0125 \\
0,7547 \\
13079,7\end{array}$ & $\begin{array}{c}0,012 \\
0,7633 \\
13338,2\end{array}$ & $\begin{array}{c}0,012 \\
0,7642 \\
13367,2\end{array}$ & $\begin{array}{c}0,0124 \\
0,7563 \\
13126,4\end{array}$ & $\begin{array}{c}0,012 \\
0,7633 \\
13338,2\end{array}$ & $\begin{array}{c}0,012 \\
0,7641 \\
13363,9\end{array}$ \\
\hline
\end{tabular}


Pode-se concluir também, por meio dos resultados apresentados na Tabela 5, que há convergência condicional da renda. Ademais, os resultados mostram que a taxa de urbanização e nível educacional contribuem positivamente para o crescimento do salário per capita regional.

\section{Conclusão}

Grande parte da literatura econômica considera a infraestrutura pública benéfica para o crescimento econômico regional. Estudos realizados para outras economias encontraram fortes indícios dos efeitos positivos da infraestrutura sobre o desenvolvimento local. Entretanto, para o caso brasileiro, os estudos feitos até então, não apresentavam efeitos positivos sistemáticos da infraestrutura pública sobre o crescimento econômico dos municípios. Neste contexto, este artigo propôs a utilização de uma nova metodologia para estimar os efeitos dos componentes da infraestrutura sobre o crescimento econômico local. A vantagem dessa nova metodologia está no reconhecimento dos efeitos espaciais entre as regiões.

Os resultados encontrados sugerem que há um forte efeito do acesso à energia sobre o crescimento econômico das regiões brasileiras. Este resultado está de acordo com o esperado, uma vez que esse componente da infraestrutura é pré-condição para a atividade produtiva.

Os efeitos das variáveis de acesso a coleta de esgoto e a abastecimento de água são mais contraditórios. Com relação à variável de acesso a abastecimento de água, não é possível extrair conclusão a respeito de seus efeitos sobre o crescimento populacional, uma vez que os resultados não são estáveis ao longo dos modelos e apresentam reversão do sinal estimado. No entanto, seus efeitos sobre o crescimento dos salários são significativos, a 1\%, estáveis e positivos.

Com relação à variável de acesso a coleta de esgoto, também há reversão de sinal quando é alterada a variável dependente utilizada como forma de mensuração do crescimento econômico regional. O crescimento populacional é a mensuração mais direta para o crescimento local, uma vez que captura o quanto os municípios estão se tornando atrativos para os habitantes e para o mercado de trabalho. Já o crescimento da renda, apesar de ser uma mensuração da variação da produtividade, possui a desvantagem de capturar também os declínios de qualidade de vida. Nesse sentido, pode-se afirmar apenas que, de acordo com os resultados encontrados, o aumento da cobertura da coleta de esgoto possui impactos positivos sobre o crescimento populacional e impactos negativos sobre o crescimento do salário per capita. Entretanto, há indícios de que a redução salarial em decorrência da maior cobertura da coleta de esgoto esteja associada à elevação na qualidade de vida regional e não a seus impactos sobre o crescimento econômico.

\section{Referências Bibliográficas}

Agénor, P. R. (2011), 'Schooling and public capital in a model of endogenous growth', Economica 78(309), 108-132.

Agénor, P. R. (2013), Public capital, growth and welfare, $1^{\text {a }}$ edição, Princeton: Princeton University Press. 
Tabela 5: Resultados do impacto da infraestrutura sobre o crescimento do salário per capita

\begin{tabular}{|c|c|c|c|c|c|c|}
\hline \multicolumn{7}{|c|}{ Modelo SEM } \\
\hline Variável / Modelo & (1) & (2) & (3) & (4) & (5) & (6) \\
\hline Água & $\begin{array}{c}0,311^{* * *} \\
(13,0662)\end{array}$ & $\begin{array}{l}0,216^{* * *} \\
(7,7695)\end{array}$ & $\begin{array}{l}0,206^{* * *} \\
(7,3556)\end{array}$ & & & \\
\hline Esgoto & $\begin{array}{l}-0,0174 \\
(-0,9843)\end{array}$ & $\begin{array}{c}-0,0183 \\
(-1,031)\end{array}$ & $\begin{array}{c}-0,0339^{*} \\
(-1,8385)\end{array}$ & $\begin{array}{l}0,0115 \\
(0,7294)\end{array}$ & $\begin{array}{l}0,0031 \\
(0,1908)\end{array}$ & $\begin{array}{l}-0,0345^{* *} \\
(-2,0096)\end{array}$ \\
\hline Energia Elétrica & & & & $\begin{array}{l}0,682^{* * *} \\
(28,366)\end{array}$ & $\begin{array}{c}0,658^{* * *} \\
(25,5165)\end{array}$ & $\begin{array}{c}0,671^{* * *} \\
(26,0074)\end{array}$ \\
\hline Taxa de Urbanização & & $\begin{array}{l}0,174^{* * *} \\
(6,6717)\end{array}$ & $\begin{array}{l}0,158^{* * *} \\
(6,0033)\end{array}$ & & $\begin{array}{l}0,062^{* * *} \\
(2,6414)\end{array}$ & $\begin{array}{l}0,0193 \\
(0,7889)\end{array}$ \\
\hline Educação & & & $\begin{array}{l}0,381^{* * *} \\
(2,9862)\end{array}$ & & & $\begin{array}{c}0,785^{* * *} \\
(6,2646)\end{array}$ \\
\hline In do Salário per capita Inicial & $\begin{array}{l}-0,26^{* * *} \\
(-45,53)\end{array}$ & $\begin{array}{c}-0,28^{* * *} \\
(-48,91)\end{array}$ & $\begin{array}{l}-0,28^{* * *} \\
(-48,01)\end{array}$ & $\begin{array}{c}-0,342^{* * *} \\
(-54,22)\end{array}$ & $\begin{array}{c}-0,348^{* * *} \\
(-51,93)\end{array}$ & $\begin{array}{c}-0,357^{* * *} \\
(-52,59)\end{array}$ \\
\hline $\mathrm{W}^{*}$ erro & $\begin{array}{l}0,2268^{* * *} \\
(15,6329)\end{array}$ & $\begin{array}{c}0,2478 \\
(0)\end{array}$ & $\begin{array}{c}0,2398 \\
(0)\end{array}$ & $\begin{array}{l}0,2148^{* * *} \\
(15,4359)\end{array}$ & $\begin{array}{l}0,2248^{* * *} \\
(15,5455)\end{array}$ & $\begin{array}{c}0,216^{* * *} \\
(15,1199)\end{array}$ \\
\hline$\sigma^{2}$ & 0,1194 & 0,1187 & 0,1187 & 0,1131 & 0,1129 & 0,1126 \\
\hline $\mathbf{R}^{2}$ & 0,6461 & 0,6456 & 0,6467 & 0,666 & 0,6656 & 0,6679 \\
\hline $\log L$ & $-3441,57$ & $-3412,9$ & $-3407,6$ & $-3037,04$ & $-3032,28$ & $-3005,88$ \\
\hline
\end{tabular}


Almeida, E. (2012), Econometria espacial aplicada, $1^{a}$ edição, Editora Alínea, Campinas.

Andrade, T. A. \& Serra, R. V. (1999), 'Crescimento econômico nas cidades brasileiras', Nova Economia 9(1).

Arrow, K. \& Kurz, M. (1970), Public investment, the rate of return and optimal fiscal policy, The Johns Hopkins University, Baltimore.

Aschauer, D. (1989), 'Is public expenditure productive', Journal of Monetary Economics 23, 177-200.

Azzoni, C. R., Menezes-Filho, N. A., Menezes, T. A. \& Silveira Neto, R. (2000), Geografia e convergência da renda entre os estados brasileiros. in: Ipea, Desigualdade e pobreza no Brasil, Ipea, Rio de Janeiro.

Barro, R. J. (1990), 'Government spending in a simple model of exogenous growth', Journal of Political Economy 98(5), 103-125.

Barro, R. \& Sala-i-Martin, X. (1992), 'Convergence', Journal of Political Economy 100(2), 223-251.

Borts, G. H. (1960), 'The equalization of returns and regional growth', The American Economic Review 50(3), 319-347.

Borts, G. \& Stein, J. L. (1964), Economic growth in a free market, Columbia University Press, New York.

Bougheas, S. (2000), 'Infrastructure, specialization and economic growth', Canadian Journal of Economics 33(2), 506-522.

Calderón, C. \& Servén, L. (2003), The output Cost of Latin America's infrastructure gap, DC World Bank, Washington.

Calderón, C. \& Servén, L. (2004), 'The effects of infrastructure development on growth and income distribution', The World Bank Policy Research Working Paper (3400).

Calderón, C. \& Servén, L. (2010), 'Infrastructure and economic development in Sub-Saharan Africa', Journal of African Economies 19, 13-87.

Calderón, C. \& Servén, L. (2014), 'Infrastructure, growth and inequality: an overview', The World Bank Policy Research Working Paper (7034).

Canning, D. (1999), 'The contribution of infrastructure to aggregate output', The World Bank Policy Research Working Paper (2246).

Chagas, A. \& Toneto Júnior, R. (2003), 'Fatores determinantes do crescimento local - evidências a partir de dados dos municípios brasileiros para o período 1980-1991', Pesquisa e Planejamento Econômico 33(2).

Cruz, A. C. (2010), 'Os efeitos dos gastos públicos em infraestrutura e em capital humano no crescimento econômico e na redução da pobreza no Brasil', Revista EconomiA 11(4), 163-185.

Elhorst, J. P. (2003), 'Specification and estimation of spatial panel data models', International Regional Science Review 26(3), 244-268. 
Elhorst, J. P. (2010), Spatial panel data models, Springer, Heidelberg.

Ferreira, P. C. (1996), 'Investimento em infraestrutura no Brasil: fatos estilizados e relações de longo prazo', Pesquisa e Planejamento Econômico 26(2), 231-252.

Ferreira, P. C. \& Araújo, C. H. V. (2006), 'On the economic and fiscal effects of infrastructure investment in Brazil', Working Paper Ensaios Econômicos da EPGE (613).

Ferreira, P. C. \& Malliagros, T. (1998), 'Impactos produtivos da infraestrutura no Brasil (1950/1995)', Pesquisa e Planejamento Econômico 28(2), 315-338.

Futagami, K. (1993), 'Dynamic analysis of an endogenous growth model with public capital', Scandinavian Journal of Economics 95, 607-625.

Gareth, J. (2013), An introduction to statistical learning, Springer, New York.

Glaeser, E., Scheinkman, J. \& Shleifer, A. (1995), 'Economic growth in a crosssection of cities', Journal of Monetary Economics 36(117-143).

Hair JR, J. F. (2005), Análise multivariada de dados, $5^{a}$ edição, Bookman, Porto Alegre.

Hulten, C. \& Schwab, R. (2000), Does infrastructure investment increase the productivity of manufacturing industry in the U.S.?, MIT Press, Cambridge.

Lee, L. F. \& Yu, J. (2010), 'Estimation of spatial autoregressive panel data models with fixed effects', Journal of Econometrics 154(2), 165-185.

Lesage, J. \& Pace, R. (2009), Introduction of spatial econometrics, CRC Press, Boca Raton.

Munnell, A. (1990), 'How does public infrastructure affect regional economic performance?', New England Economic Review 69-103.

Mussolini, C. C. \& Teles, V. K. (2010), 'Infraestrutura e produtividade no Brasil', Revista Economia Política 30(4), 645-662.

Roback, J. (1982), 'Wages, rents, and the quality of life', Journal of Political Economy 90(6), 1257-1278.

Rogerson, P. (2001), Statistical methods for geography, Sage.

Rosen, S. (1979), Wages-based indexes of urban quality of life, John Hopkings Univesity Press, Baltimore.

Sánchez Robles, B. (1998), 'Infrastructure investment and growth: some empirical evidence', Contemporary Economic Policy 16(98-108).

Turnovsky, S. (1996), 'Fiscal policy, adjustment costs, and endogenous growth', Oxford Economic Papers 48, 361-381. 


\section{Apêndice}

Censos Demográficos de 1970, 1980, 1991, 2000 E 2010. Instituto Brasileiro de Economia e Estatística.

Figura 2: Percentual de domicílios com acesso ao abastecimento de água pela rede geral por Unidade da Federação
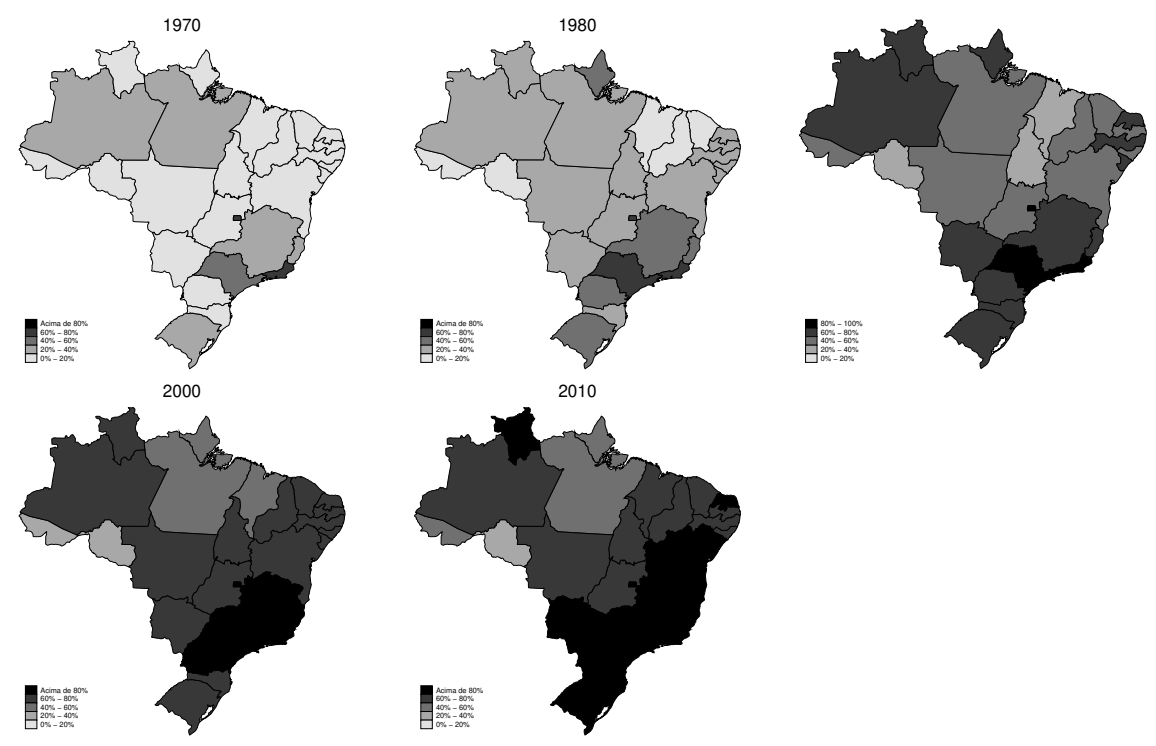

Figura 3: Desvio-padrão do percentual de domicílios ao nível municipal com acesso ao abastecimento de água pela rede geral por Unidade da Federação
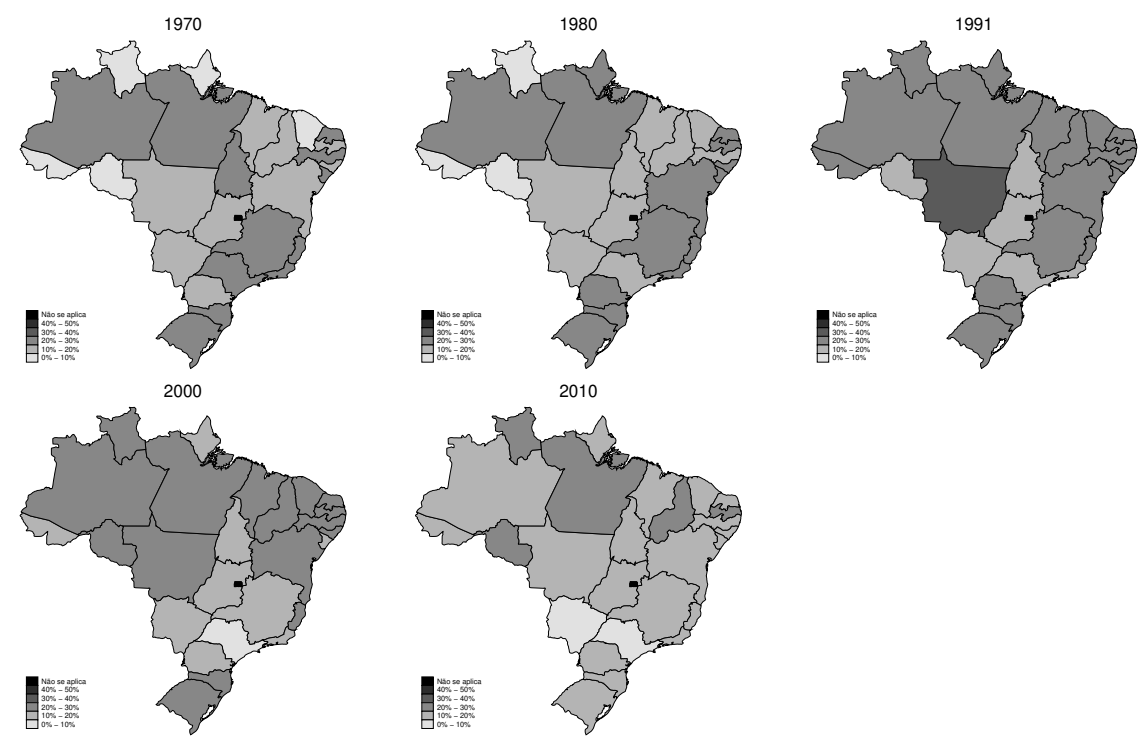
Figura 4: Percentual de domicílios com acesso à coleta de esgoto pela rede geral por Unidade da Federação
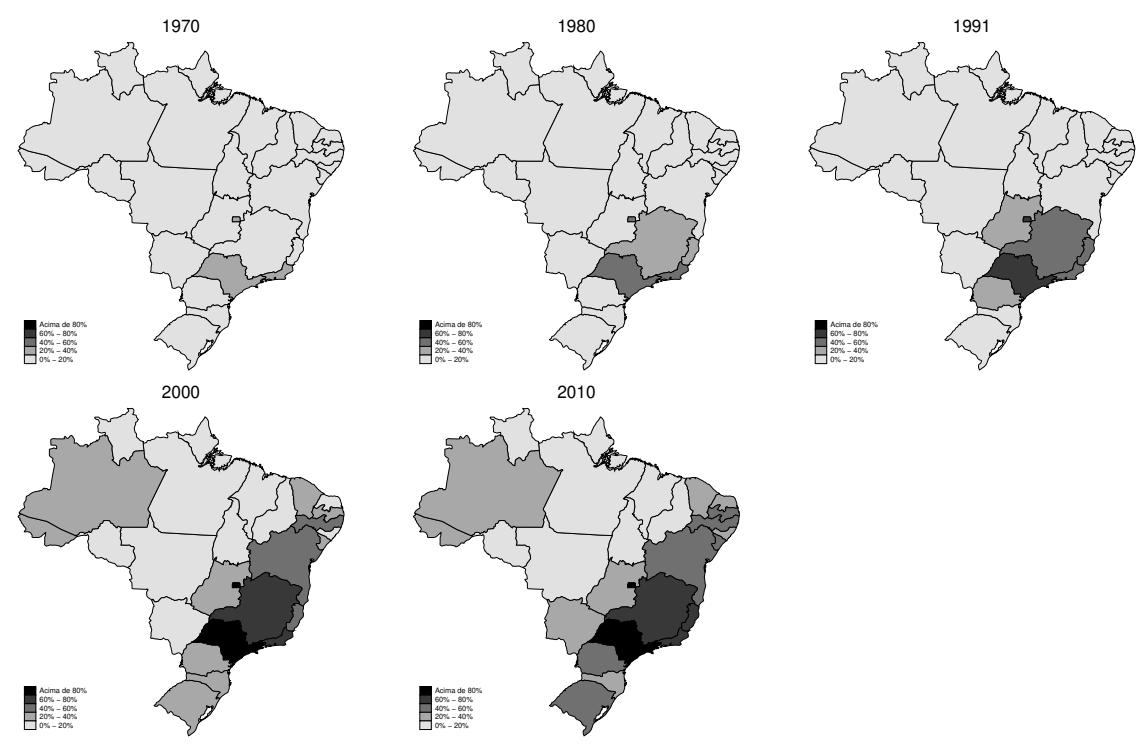

Figura 5: Desvio-aadrão do percentual de domicílios ao nível municipal com acesso à coleta de esgoto pela rede geral por Unidade da Federação
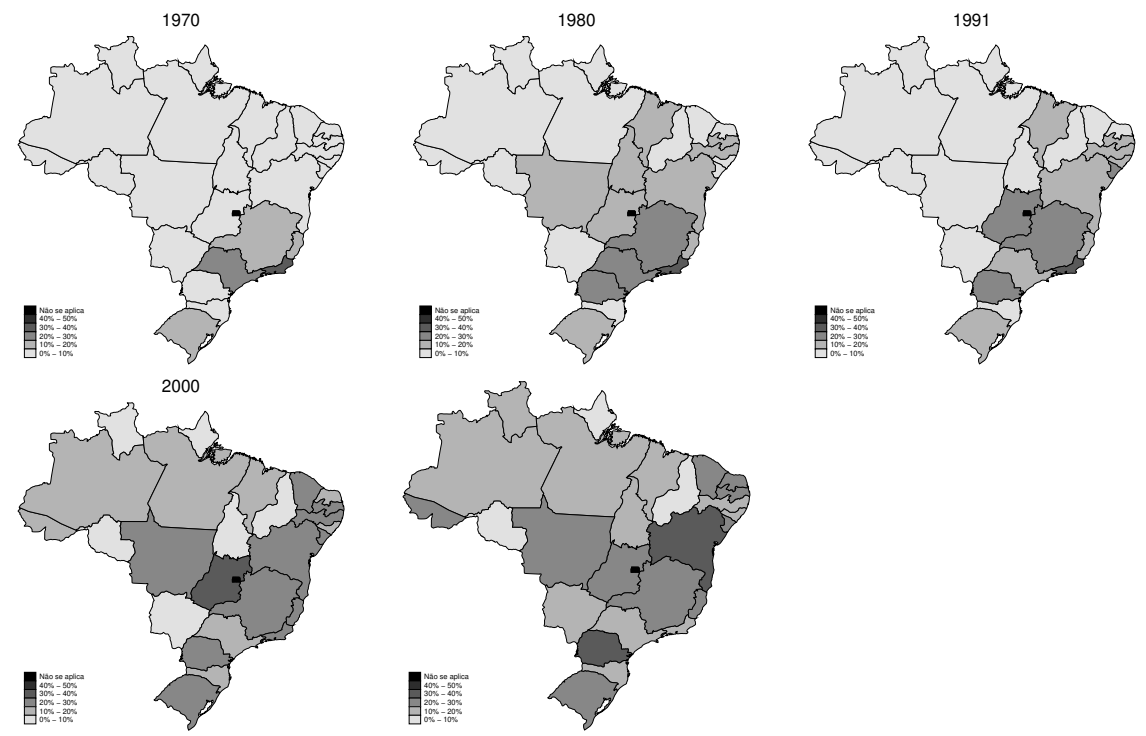
Figura 6: Percentual de domicílios com acesso à energia elétrica fornecida pela companhia distribuidora por Unidade da Federação

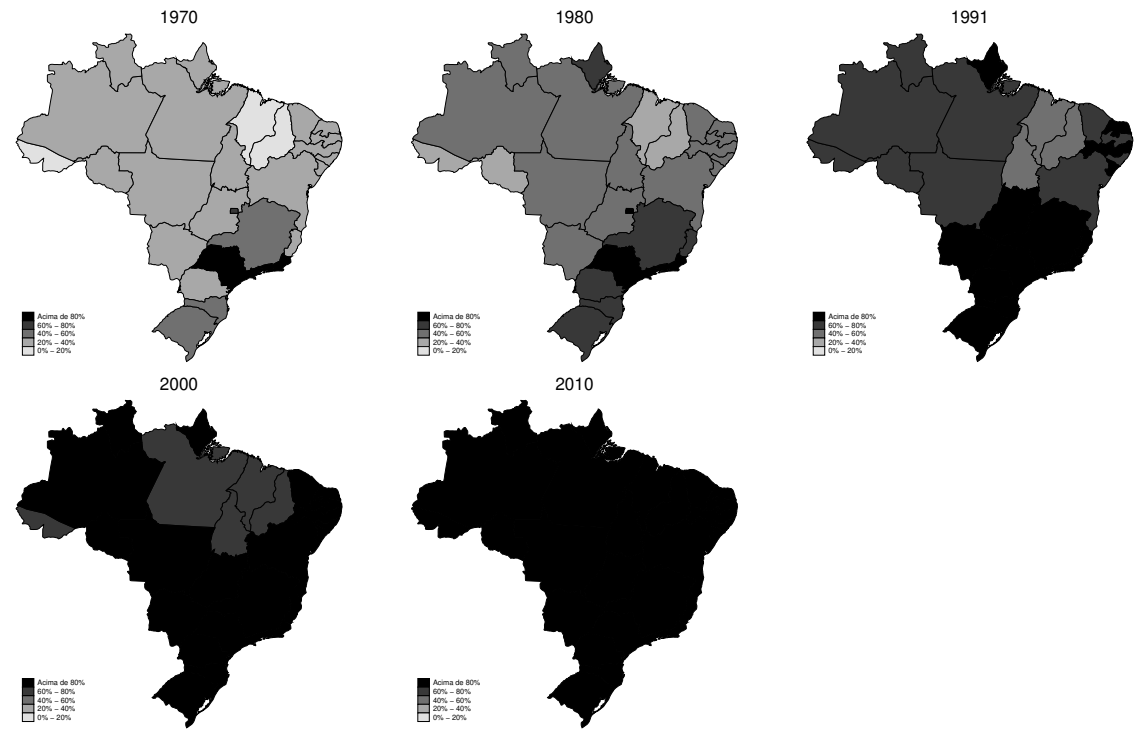

Figura 7: Desvio-padrão do percentual de domicílios ao nível municipal com acesso à energia elétrica fornecida pela companhia distribuidora por Unidade da Federação
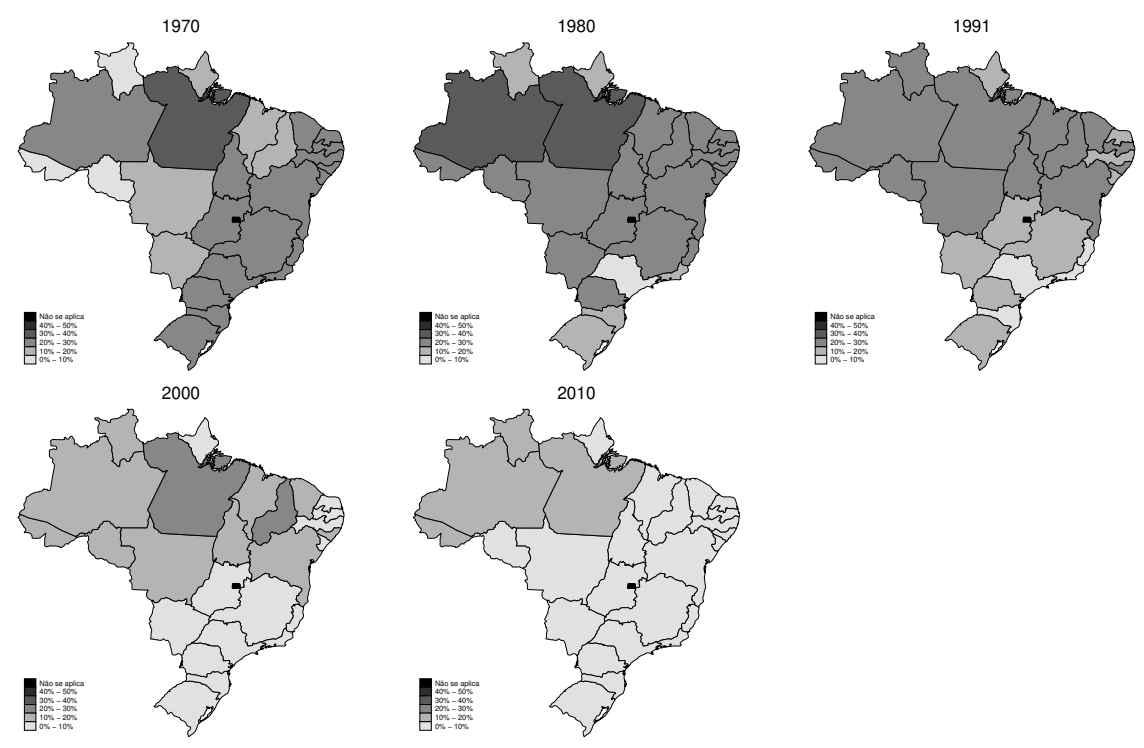
